\title{
LEGAL BARRIERS TO 3D CADASTRE IMPLEMENTATION: WHAT IS THE ISSUE?
}

Serene $\mathrm{Ho}^{1^{*}}$, Abbas Rajabifard $^{1}$, Jantien Stoter ${ }^{2}$ and Mohsen Kalantari ${ }^{1}$ sereneh@unimelb.edu.au, abbas.r@unimelb.edu.au, J.E.Stoter@tudelft.nl, saeidks@unimelb.edu.au

${ }^{1}$ Department of Infrastructure Engineering, University of Melbourne, Australia

${ }^{2}$ OTB, Delft University of Technology, The Netherlands

${ }^{*}$ corresponding author

Corresponding Author:

Serene Ho

A: Centre for SDIs and Land Administration

Department of Infrastructure Engineering

University of Melbourne

Australia, VIC 3010

T: +61383446771

\section{ABSTRACT}

The ways society use and occupy space occur in multiple dimensions; however, the ways we manage and administer space relies on two-dimensional information representations (2D). The legal ambiguity and administrative limitations inherent in such practices are becoming increasingly pronounced within land administration especially for urban areas. In response, a research domain has emerged - termed by specialists as '3D Cadastres' - to seek greater correspondence between the administration of legal land and property (parcel) boundaries and the reality of physical bounds of structures themselves. Within this corpus of literature, advances in the technical domain are evident. However, other areas of research have not experienced the same degree of attention, with a particular lag in analysis of legal issues: this apparently explains the lack of progress in the realisation of operational 3D cadastres. However, given many countries actually already administer ownership of 3D property within current statutory frameworks, is the continued concentration on legal issues a red herring? Are legal issues significant barriers to implementation, and if not, what other considerations are there?

This position paper, comprising two main sections, aims to consider, clarify and reconceptualise the significance of the law as an obstacle to implementation of 3D cadastres. It does this by firstly reviewing the legal issues articulated within the literature and examining the extent of its impact using current practical examples. This leads to the conclusion that finding alternative methods and processes to overcome perceived legal issues actually facilitates progress towards 3D property registration and therefore, 3D cadastre implementation. This challenges the dominant assumption that legal issues are a significant barrier. The paper then proposes to consider the influence of legal issues through an institutional lens, as a way of gaining other insights into how legal issues can influence 3D cadastre implementation. The introduction of institutional theory and a theoretical framework provides a way to reconceptualise the role of legal issues in 3D cadastre implementation. The framework is further used as a sensitising mechanism for discussing broad-based institutional issues that have as yet, not been given significant consideration in the literature. The paper concludes with a response to the main research question and the proposition that significant barriers to 3D cadastre implementation lies not in technological or legal issues, but the more fundamental social and cultural issues that make up the institutional framework underpinning cadastral systems.

Keywords: 3D cadastres, legal issues, implementation, institutional issues, organisational issues 


\section{LEGAL BARRIERS TO 3D CADASTRE IMPLEMENTATION: WHAT IS THE ISSUE?}

\section{INTRODUCTION}

Our use and occupation of space has always had multi-dimensional characteristics - terrestrial (2D), vertical (3D) and temporal (4D). Until recently, the instruments and practices used to manage information about land and property rights, restrictions and responsibilities (RRRs) with multiple dimension attributes rely on paper plans where only flat projections are possible - be it horizontal or terrestrial boundaries or isometric perspectives of structures. Land administration systems around the world are predicated on a tradition of 2D representation of property boundaries, often with a variety of other property interest information recorded as notations. The limitations of these practices for representing the legal and administrative status of vertically defined properties are now becoming apparent, especially with increasing use of multi-storeyed developments to manage limited space to service population needs (e.g. Ossko, 2001; Mitrofanova, 2001; Sandberg, 2001).

In response, a research domain known as '3D Cadastres' has emerged. According to the website of the International Federation of Surveyors (FIG) Working Group on 3D Cadastres (www.gdmc.nl/3DCadastre/), this research domain is concerned with the "registration of the legal status in complex 3D situations" (FIG, 2012). In support of this, research efforts have been focused on "legal, institutional and technical aspects", of which the technical developments have been significant. Over the last decade, initial considerations about design and requirements have progressed to the development of prototype 3D cadastral systems (e.g. Russia, Spain) and a data model (Land Administration Domain Model) recognised as an ISO standard in 2012. In contrast, the non-technical areas of research have lagged behind, predominantly legal and organisational issues (Paulsson and Paasch, 2011). This is despite broad support from the research community that the crux of the 3D cadastre issue is a legal one and not a technical one (Fendel, 2002). The outcomes of the second 3D cadastre workshop in 2011 stated as much, underscoring the primacy of an appropriate legislative framework to underpin 3D cadastral systems:

"if a legal system does not provide the instruments to create $3 D$ property, there is no need for a $3 D$ cadastre at all. On the other hand a $3 D$ Cadastre itself does not make $3 D$ property rights possible" (Banut, 2011, p.3).

However, many countries around the world (e.g. Australia, Sweden, the Netherlands, Singapore) actually have provisions for ownership of 3D property (e.g. Williamson 2002; Stoter, 2004; Rajabifard et al, 2012). Yet according to the FIG Working Group on 3D Cadastres, "no country in the world has a true 3D Cadastre, the functionality is always limited in some manner" (FIG, 2012). The overarching question that this paper will seek to examine is therefore: what impact do legal issues have in the implementation of a 3D cadastre?

The paper comprises two main parts: firstly, a review of the legal issues that have so far been raised within $3 \mathrm{D}$ cadastre research is analysed in the context of current practices to contest the dominant assumption that legal issues pose a significant barrier to implementation, given evidence in many jurisdictions that demonstrate how current legal frameworks are "stretched" to register 3D properties. Additionally, the continued distinction between legal and institutional issues in the research domain, when legal issues are typically considered as part of a broader institutional framework, has not facilitated a more holistic understanding of the relationship between legislation and stakeholder behaviour, which hinders or enables implementation efforts.

The second part of the paper therefore begins by providing a short theoretical perspective on institutional theory as a precursor to introducing an institutional framework. Institutional theory is concerned with the persistent aspects of social structures, and how these structures (such as routinised behaviour, norms and legislation) come to be regarded as the legitimate or authoritative way to act. Institutional theory has helped researchers in both organisational and technological domains explain issues of both adoption processes and resistance to change. The framework introduced in this paper is used to reconceptualise the role of legal issues, but as well to provide a sensitising mechanism for discussing broader institutional issues that have as yet, not been given significant consideration in the literature. The consideration of these issues through an institutional lens serves not only to build a response to the main research question, but also to validate the proposition that significant barriers to implementation of 3D cadastres lie at the organisational and institutional levels. This provides a starting point for stimulating a broader discussion on the research agenda relevant to institutional aspects of 3D cadastres.

\subsection{Research Standpoint}

The definition of a cadastre has long been associated with a function as a repository of land and propertyrelated information (e.g. the Austro-Hungarian cadastre and the Napoleonic cadastre of the $19^{\text {th }}$ century, 
whose original functions as tools of survey and census to produce registers of information are still relevant today). Definitions of modern cadastres however, are perhaps more aligned with the content of the information itself and its technological implementation. For example, Figure 1 (left) below shows the cadastre as a concept comprising individual pieces of information relevant to land and property, and the implementation of this concept is through the use of technology to link, integrate and visualise land and property information.
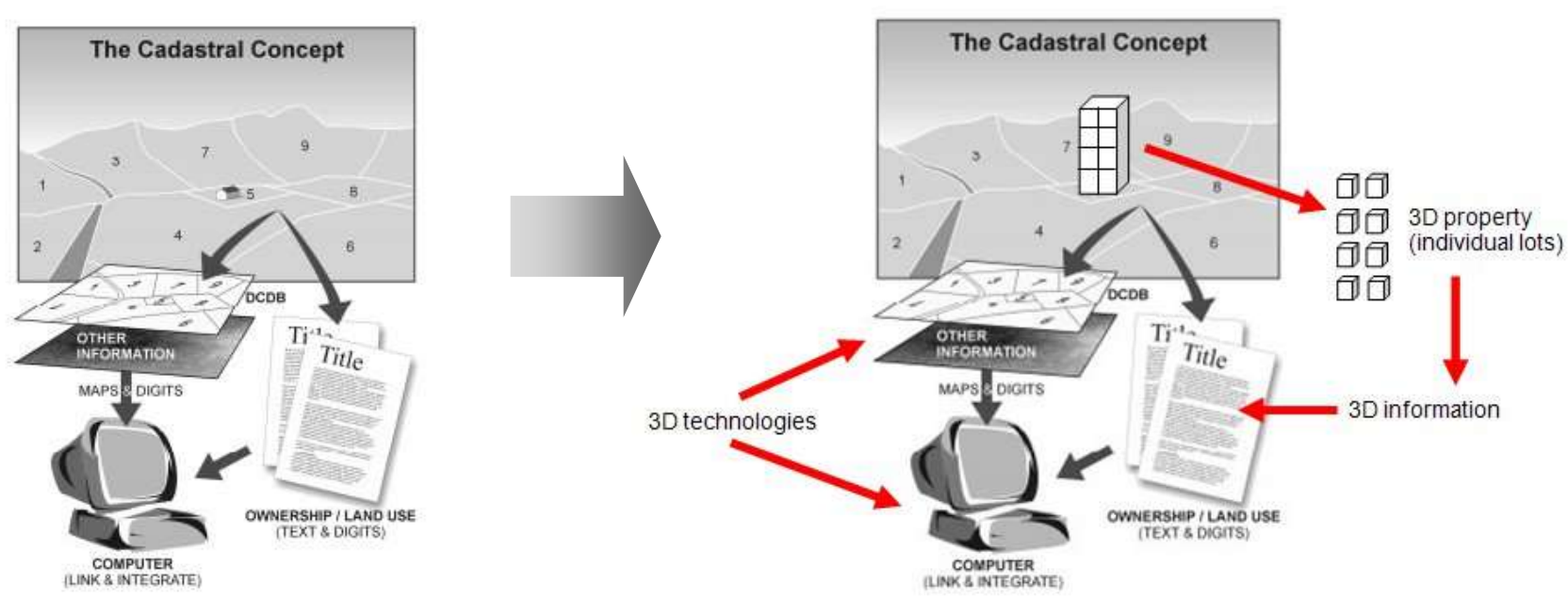

Figure 1. The Cadastral Concept (FIG, 1995) and adapted 3D cadastral concept.

This paper is written from the perspective that a cadastre is fundamentally a cognitive construct used to administer and manage information about land and property rights, restrictions and responsibilities (RRRs) through a registration process. This process depends on the use of conceptual points and lines to form land and property (land parcel) boundaries. Given the strong cognitive aspect, one of the ways that cadastral information is accorded with the real world is to visualise it in a physical format. The paper therefore takes the standpoint that ' $3 \mathrm{D}$ cadastres' as a concept encompasses primarily the potential evolution of the information required for the registration process of vertically differentiated parcel boundaries, but secondarily, it includes an evolution of the technologies required to support the physical representation of cadastral information in 3D (see Figure 1 above).

\section{CURRENT CADASTRAL SYSTEMS AND 3D PROPERTY}

In line with one of the fundamental purposes of a cadastre, that is to support tenure security, one of the key outcomes of the working session on legal issues at the first 3D cadastre workshop in 2001 was (Fendel, 2002, p.4):

The main target, from a legal point of view, is to make these rights certain, and transferable. By doing this we make the multi use of land practical, possible, and attractive to the market.

This primary issue of rights drives the legal mandate, where the objective is to establish and define land and property RRRs unambiguously.

\subsection{Defining the Legal Factors}

There are several ways the law can affect the legitimacy of 3D property. So far, the literature has mainly concentrated on issues best dichotomised as being addressed at the broad level of public or private law. These include, but are not limited to:

- the concept of a 3D property, its legal status and classification of associated rights (e.g. Stoter and Zevenbergen, 2001; Fendel, 2001; Stoter, 2004; Paulsson, 2007; Paulsson, 2008; Karki et al, 2010);

- questions raised over the legislative framework required to support autonomous registration of 3D property (e.g. Stoter and Zevenbergen, 2001; Huml, 2001);

- jurisdictional legislative limits and considerations (e.g. Huml, 2001; Sandberg, 2001; Stoter and Ploeger, 2003; Papaefthymiou et al, 2004; Aien et al, 2011; Tan and Hussin, 2012);

- registration of real property vs. physical objects (e.g. Ossko, 2001);

- effect of public law on private rights (Navratil, 2012); and

- common property regimes (Paulson, 2012). 
Figure 2 below shows a graphical representation of the legal issues covered so far in the literature and their inter-relationships.

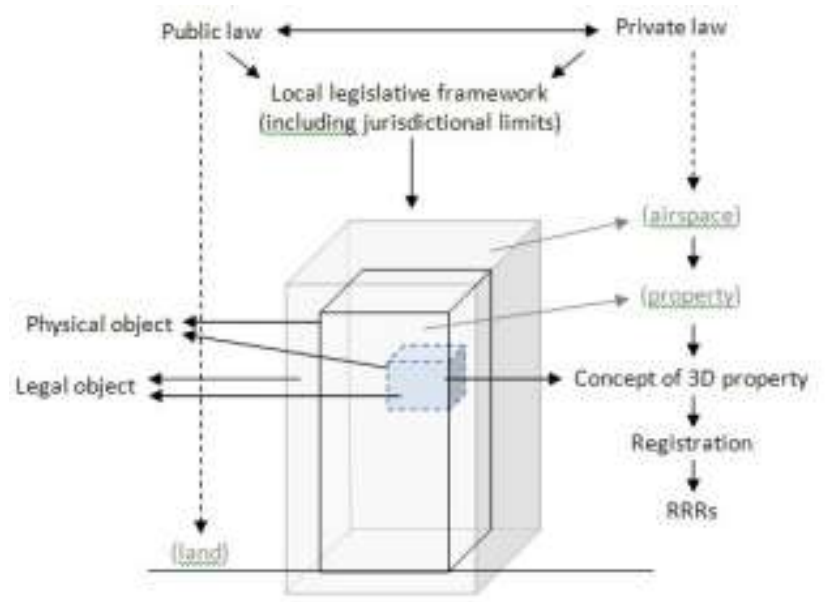

Figure 2. Graphical representation of legal issues relevant to 3D cadastres.

In general, the legal issues identified in the literature appear to be mostly concerned with 3D property legislation. The literature supports the need for 3D property to be established administratively, i.e. provided with legal status and establishes its relationship with other RRRs. Inherent in the establishment of rights is the issue of registration and the instruments that support the ability to unambiguously define the extent of rights. Therefore, secondly, the law must support the geometric definition and location of these RRRs in a clear and consistent manner. This requires some prescription (legal or regulatory) to standardise methods for the definition of 3D property RRR boundaries and to locate its position relative to boundaries of other RRRs. The introduction of a vertical dimension is therefore logical, facilitating the articulation, representation and relationship of RRRs in strata, i.e. "rights with 3D characteristics" (van Oosterom et al, 2011, p.17).

It is unsurprising that the literature on legal issues has focused heavily on the concept of 3D property itself (e.g. Stoter and Zevenbergen, 2001; Fendel, 2001; Stoter, 2004; Paulsson, 2007; Paulsson, 2008; Karki et al, 2010) as well as on how current legislative frameworks support autonomous registration of 3D property (e.g. Stoter and Zevenbergen, 2001; Huml, 2001). There is international variance across what constitutes stratified RRRs, but Paulsson (2007, p.32) has defined the main types to be: independent 3D property, condominium (apartment ownership), indirect ownership and granted rights. These categories reflect diversity in perspectives and approaches towards ownership, boundary definition, property management and common property (Paulsson, 2012) but nonetheless demonstrate that 3D property RRRs are already supported by legal instruments, albeit with some degree of pluralism.

The need for definitive geometric definition of RRRs is also important and is certainly not specific to strata properties. For example, in jurisdictions where the concept of ownership rights includes property, for registration purposes layered legal property objects (e.g. apartment units) typically rely on physical structures to support its definition (general boundaries), but property remains in essence, cognitive concepts. Therefore in these jurisdictions, if a block of apartments burns down, the right to the space previously articulated by the apartment structure (walls, floors, ceilings, etc) will remain. But how accurately could this right be reestablished?

\subsection{Current Practices}

In some countries, there is no doubt that legal reform is required because 3D property cannot be established as a secure, tradeable entity. Even then, alternative methods are being developed and used which, although meeting current registration requirements, leave a question mark over future tenure security due to legal ambiguity. In Finland where 3D property cannot be formed, the use of alternative methods of registration and rights definition circumvents this issue (Vitikainen and Hiironen, 2012). Similarly in Indonesia, registration of $3 \mathrm{D}$ condominium rights is possible in the current $2 \mathrm{D}$ system with the use of a $3 \mathrm{D}$ tag, but the technical ambiguities around the boundary definition of these rights poses a potential problem around legal and secure access to the 3D property (Hendriatiningsih et al, 2012). Some countries have already undergone recent reform to support 3D property, which has been beneficial in providing greater clarity and ultimately better tenure security. For example, China introduced a new property law in 2007 to support 3D properties and 
associated rights and Hungary enacted legislative modifications in 2011 to current acts to ensure clarity on the legal establishment and definition of 3D property and associated rights (Iván, 2011).

In other instances, it is unclear as to whether reform is required and it may be a case of erring on the side of caution. For example, in Poland, 3D property can be registered in the current system but researchers believe legal reform should be considered for the realisation of 3D cadastre in the country (Bydlosz, 2012). To overcome the limitations of 2D cadastral systems, many countries establish 3D properties by using existing juridical boundaries of the base 2D land parcel eg. The Netherlands and Australia (eg. Stoter and Zevenbergen, 2001). A recent comparative study by Dimopoulou and Elia (2012) looking at the function of land law in Greece and Cyprus relevant to RRRs also provides another potential situation where legislative reform lies in a grey area: in this instance, customary traditions that bestow 3D property rights are still practised even though they contravene the civil code.

As more countries move towards developing prototype systems and implementing 3D cadastre pilots, it is becoming evident that legislative reform may not be as significant a factor for progress as once thought. Addressing the primary issue of 3D property rights, current research shows that in many countries, legislation originally designed with 2D properties in mind are flexible enough to accommodate 3D properties as is the case in Sweden, The Netherlands and the Australian states of New South Wales, Queensland and Victoria (Paulsson, 2012; Stoter et al, 2012; Karki et al, 2013). In such instances, the need for new legislation is not immediately apparent.

There can also be little fundamental difference in the registration of 2D or 3D properties and their resulting legal status (Sandberg, 2001). For example, Paulsson (2012) found that in both the Australian state of Victoria and Sweden, 3D property is subsumed under legislation that was initially designed for 2D property (albeit in these instances, legislation tended to be more vague and non-prescriptive). In Victoria, mapping of strata rights are handled administratively within the current registration regime but there is no geometric element of its boundaries except the plan drawings for each floor level (not drawn to scale). The absence of geometrically defined boundaries of the 3D property and its RRRs do not detract from its legal status, although can exert a negative impact on information management processes.

The sum of the textual, geometrical and graphical information on title and survey plans provides the basis for establishing legally binding status of these rights. The laws that would underpin a cadastre can therefore be direct in its definition of what is required to support ownership (e.g. the Transfer of Land Act and Subdivision Act in the Australian state of Victoria) or indirect, for example by exerting influences on the use of the land (e.g. Planning and Environment Act in Victoria). What we want legal support for can also be a product of political systems and social and cultural approaches to land and property. For example, reflecting the socialist system in China, laws regarding security of tenure relate to building and land use not ownership, since land is either state-owned or collectively-owned (i.e. not freehold). As such, the Chinese cadastre includes not only land parcels, but buildings as well. In contrast, in a common law system such as that existing in Australia, the English concept of real property is upheld where ownership of land is key - physical structures on the land are not a consideration and are not recorded in the cadastre. Therefore, proper definition of the purpose for legal support needs to be a necessary first step.

\subsection{More Than Just a Legal Issue: A Continuum of Issues}

Although legally supported, methods used to register 3D properties into 2D parcel-based systems have acknowledged pitfalls. For example, Stoter et al (2012) found that 3D properties are registered via 2D registration practices in The Netherlands by which ambiguity, as well as errors, is potentially introduced into the register by the use of numerous 2D parcels to register a single 3D property (that spans multiple parcels). Also, using current methods to register complex properties (i.e. multiple 2D parcels used) may require localised situational knowledge to assist in interpretation due to the limited representation and information held in land registers (Stoter et al, 2012). These practices, while viable, can potentially have legal ramifications in the future as it affects the ability of future stakeholders to unambiguously interpret the legal extent of a 3D property. A question arises as well as to whether current dependence on 2D boundaries, which can be construed as an impediment in moving towards a 3D paradigm, is a product of the law, the limitations of technology and information systems, or a consequence of relying on familiar cadastral processes that have proven their merits for years (even though alternative registration methods that take account for the complexity of 3D cadastre situations might be at hand)?

Without a doubt, the mapping of legal and physical objects in 3D will prove beneficial for a range of purposes and have been linked to multi-purpose cadastres and broader urban applications (Rajabifard et al, 2012). And from the previous literature review, it can be concluded that current rules (laws, operating standards, etc) are often not explicit on 3D legal object mapping. However, do existing legal frameworks prohibit extensive 3D legal object mapping? The answer is potentially no. Using the ability to establish, define and 
register 3D property and its rights as a barometer, we find that many current legal frameworks do not need to be changed and this conclusion echoes the outcomes of the working sessions on legal aspects at both the 2001 and 2011 3D cadastre workshops (Fendel, 2002; Banut, 2011). Additionally, the findings of the FIG questionnaire undertaken from 2010 to establish the status of 3D cadastres around the world concluded that registration of $3 \mathrm{D}$ parcels was operationally possible in general and that the law is not explicit on vertical limits of rights in many countries (who embrace a "heaven-to-hell" approach unless otherwise stated) (van Oosterom et al, 2011).

In themselves, issues surrounding establishment and definition of rights are fairly absolute and contained. The challenge arises because rights are cognitive concepts that are socially constructed and require the acceptance of the community as part of the validation of their existence. Owners use administrative information, plan drawings and survey measurements and interpret these within a specific legal context to accord this information with what they can see physically to help them to understand the boundaries of their RRRs. This helps them to define where their ownership rights end and where their neighbours' rights begin. In that sense, improved structuring and representation of RRR information is important both from a management and use perspective, but may not necessarily be wholly legal issues. Clarity of RRRs is the main driver for determining if legal reform is required - if the degree of clarity (or lack thereof) is acceptable to a jurisdiction, then it is likely that reform is not a prerequisite for secure legal support for 3D properties and RRRs. The degree of clarity is likely to be a function of a jurisdiction's practices and requirements.

If current legislation does not permit 3D property registration, then it seems logical to assume that a lack of appropriate legislation would impede the collection of property and RRR information relevant to vertically differentiated parcels. However, the current practices described previously show a range of alternative methods of registration being developed or practised, either by exploiting inherent flexibility within current legal frameworks, or despite the lack of legislation, to overcome operational limitations. There is no doubt that a lack of legislation will have some impact on the implementation of 3D cadastres but its extent of its influence is debatable since the immediate pressure of needing to register 3D properties to support land markets means that cadastral organisations must find work-arounds and develop alternate methods. The issue here regarding these registration methods appear more to be their longer-term integrity.

Ironically, this issue of longer-term integrity should spur innovation of more suitable processes and leveraging of the opportunities afforded by 3D technologies. Yet many of the alternative methods continue to be based on robust, extant 2D-based processes and technologies, which while possibly being legally valid, are increasingly acknowledged to be inefficient and prone to potential ambiguity and errors. A more pertinent question that could be raised regarding implementation of 3D cadastres appears to be: what is contributing to these path dependencies within cadastral organisations and relevant stakeholders? Is it because these methods are currently legally valid (as the law is considered a way to legitimise behaviour within any society)? What about in jurisdictions that currently do not have legislation - what explains the persistent use of 2D-based processes and technologies?

It is pertinent to note here that within the 3D cadastre research domain, legal issues are often considered as a standalone topic differentiated from other institutional issues, when the law itself has always been considered a type of institution. At this juncture, the paper provides a brief overview of institutional theory and introduces a theoretical institutional framework. Reconceptualising the role of legislation within this framework will not only serve to provide another perspective on the role of legislation as a barrier to implementation by reinforcing path dependencies, but will also serve to elucidate other fundamental sociological barriers to change that exist at organisational or even individual level. A holistic understanding of the role of institutional aspects and its influence on behaviour will contribute additional and necessary insights for identifying a change path trajectory towards the adoption of new processes to support the implementation of 3D cadastres.

\section{THEORETICAL PERSPECTIVE ON INSTITUTIONS}

Institutions exist everywhere and are a fundamental part of social interactions because they constitute the social structures that evolve from local customs and beliefs, which through repetition, strengthen to form normative rule-based structures (both formal and informal) that prescribe or preclude behaviours in actions at all levels of society (e.g. Ostrom, 2005). Institutional theory, with its emphasis on shared systems of values, norms, rules, beliefs and assumptions have helped researchers in both organisational and technological domains explain issues of both adoption processes and resistance to change (e.g. Nelson, 1988; Orlikowski and Robey, 1991; Dosi, 1992; King et al, 1994; Edquist, 1997; Damsgaard and Lyytinen, 2001; Nelson and Nelson, 2002). However, institutionalisation also produces path dependency, which is one of the key issues in innovation literature, where behaviour is locked in due to its repetitive nature (regardless of whether this 
behaviour provides a competitive edge) and therefore poses an obstacle to change (Leavitt and March, 1988; Powell, 1991; Bassani and Dosi, 2001; Hargadon and Douglas, 2001; Fagerberg 2004).

The relationship between innovation and institutions is essentially a tension arising from the interaction of two diametrically opposed social forces: stability (institutions) and change (innovations). This relationship is described by Hargadon and Douglas (2001, p.476):

Introducing change into otherwise stable social systems is a risky endeavour, but this is exactly what entrepreneurs with potentially significant innovations must attempt to do. To be accepted, entrepreneurs must locate their ideas within the set of existing understandings and actions that constitute the institutional environment yet set their innovations apart from what already exists.

Therefore, understanding how institutions are created, evolve and wane is critical to fostering both stability and adaptability within organisations in the face of technological change.

\subsection{Theoretical Variants}

There are now many different variants of institutional theory, including new and old institutionalism and historical institutionalism (Hollingsworth, 2000). Peters (2000) identified seven versions of institutionalism: normative, rational choice, historical, empirical, sociological, and international regimes and interest groups as institutions. The commonality between all these versions is that they all emphasise the influence of structures on behaviour and action and its persistence across time - this provides a somewhat predictive component to institutional analysis. The differences have been attributed to the sources of preferences that structure action, for example, internal versus external influences (endogenous vs. exogenous) (e.g. Zucker, 1977; Meyer and Scott, 1994).

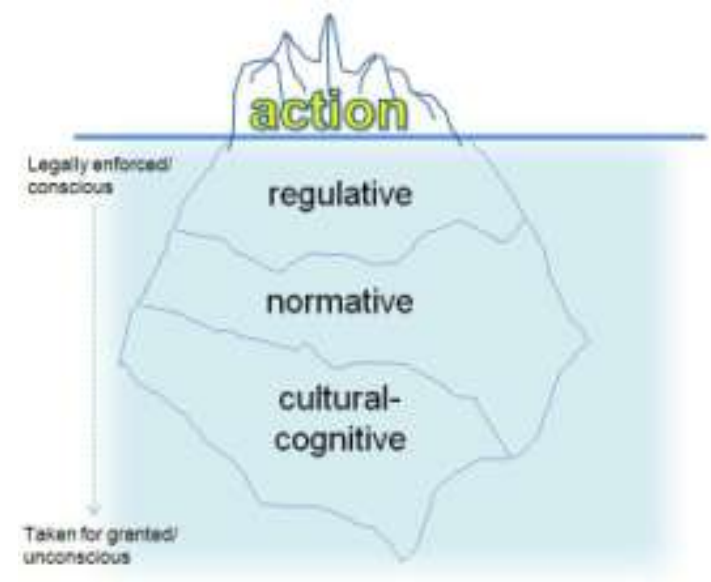

Figure 3. Scott's three pillars of institutions and its relationship to action conceptualised as an iceberg diagram (Scott, 2001. P.52)

Recognising the plurality of the concept and its theoretical perspectives, Scott (2001) developed his 'Three Pillars' framework using the broad categories of 'cultural-cognitive, normative and regulative' systems as the basis for explaining institutional endurance. His decision to link culture with cognition "recognises that internal...processes are shaped by external cultural frameworks" (Scott, 2001, p.57). In a way, these systems exist as a hierarchy, where the cultural-cognitive elements provide the foundation for establishing normative ones and on to that, regulative elements of social structures. These three 'pillars' represent influences on behaviour that spans the continuum of consciousness. The iceberg diagram in Figure 3 represents how Scott's concept of institutions influences behaviour. Therefore, his definition of institutions as:

social structures that have attained a high degree of resilience (and are) composed of culturalcognitive, normative, and regulative elements that, together with associated activities and resources, provide stability and meaning to social life (Scott, 2008, p.48)

will be adopted in this paper as it allows for the full range of social, cultural and cognitive influences on behaviour to be included within the concept of institutions. Scott's (2001) conceptualisation of the regulatory aspects as being at the more 'conscious' end of the spectrum of institutional influence on action also goes 
some way towards explaining the emphasis on legal issues within the 3D cadastre research domain. This is however, only one aspect of institutions.

\section{POTENTIAL INSTITUTIONAL FACTORS IN REALISING 3D CADASTRES}

Using Scott's three pillars framework as a sensitising mechanism, this section considers some of the current practices described in Section 2 through an institutional lens to develop other insights in response to the main research question of this paper. It also raises other potential areas of institutional inertia that could prove to be limiting factors in progressing implementation of 3D cadastres. Although these issues are generic in nature, they are an intersection of two key umbrella themes relevant to the topic: proven institutional (including organisational) issues endemic to land administration and proven influences on successful adoption or diffusion of technological innovation in general. While not definitive, these issues are proposed to provide additional support and validity to the proposition that the more significant barriers to implementation of 3D cadastres lie at the organisational and perhaps even individual levels, providing a starting point for stimulating a broader discussion on the research agenda relevant to institutional aspects of 3D cadastres.

\subsection{Regulatory Elements}

The fact that many jurisdictions have developed alternative practices for 3D property registration by exploiting the flexibility within current legal frameworks provides a starting point for reconceptualising the impact of legal issues on 3D cadastre implementation. The tendency for current legislation to be vague and non-prescriptive already suggests it has a limited impact. Instead of posing as a regulatory limitation, it is possible that legal frameworks are actually facilitating progress towards realising 3D cadastres by functioning as a means of shared sense-making amongst stakeholders with regards to new registration situations posed by complex 3D properties. The institutional perspective considers legislation not only to be a regulatory element, but also a social structure that displays cultural-cognitive and normative elements that are equally significant in establishing legitimacy for certain types of behaviour (Suchman and Edelman, 1996).

The law is certainly an important part of cadastral organisations, providing a legal mandate for operation and therefore to some extent, defining its form and its relationship with other external stakeholders. This in turn can have other regulatory impacts which to date, have not been raised in the literature. For example, many countries currently have land registries and cadastres situated under one organisation and therefore cadastral innovation may be easier to effect through regulatory mechanisms. However, there are just as many countries, like Malaysia and Greece, where multiple agencies are involved in the collection and management of cadastral as well as other land and property information (Tan and Hussin, 2012; Dimopoulou and Elia, 2012). For example, the Philippines provide a classic example of duplication and overlapping of authority and administration since four agencies are authorised to issue titles and two can approve survey plans (Burns, 2006). Alternatively, these tasks could be undertaken across different levels of government e.g. in Poland (Bydlosz, 2012). A third situation requiring multiple agency involvement is where land registers and building registers are set up and managed independently (e.g. Spain, Poland, Denmark and the Czech Republic). These arrangements imply potential legislative and bureaucratic barriers, especially if there is no harmonisation of legislation across multiple agencies. In any of these instances, endemic coordination and collaboration issues would likely exist, which would surely impact upon effective and efficient administration and governance of registry information, as well as any move to implement changes to policies and procedures to support progress towards 3D cadastres.

Cadastral organisations are also typically public sector organisations (Kaufmann and Steudler, 1998), which tend to negotiate change through extensive formal processes, leading to protracted implementation timelines. For example, a move to introduce digital plans of subdivision (known as ePlan) in Australia has met with slow progress. In 2003, the national ePlan working group was established by the Intergovernmental Committee on Surveying and Mapping (ICSM), which developed a national standard for cadastral data transfer. The project implementation phase commenced in 2007 nationwide, but in the state of Victoria, the actual design, testing and use of the drafting (CAD) software and data transfer protocol only commenced at the end of 2010 with a small group of surveying firms in the state. Currently, enhancements are still being made to the CAD software supporting ePlan and its relevant data transfer processes and ePlan is not yet available to the industry.

\subsection{Normative Elements}

Normative elements are predominantly concerned with values and norms which help to facilitate behaviour that is desirable, preferred or, to some extent, expected behaviour, through a sense of obligation towards the dominant social group (Scott, 2001). 
dominance of the 2D paradigm in representing land and property information across different relevant professions. Normative elements could also include routinised registration process and current operating standards. In Australia, current land administration systems are based on graphical practices - plan drawings, cross-sections, etc. A move towards a 3D environment demands the use of digital information to fully leverage its benefits in improved querying abilities, reuse of data and representation of information and this requires wholesale changes to how information is collected, drawn, exchanged and even registered -a fundamental shift in the norms and values relevant to collaboration, visualisation and analytical processes. Various initiatives are already underway to develop necessary infrastructure: in the Australian state of Victoria, infrastructure developed to support digital transactions in the lodgement and management of planning applications to Council (known as the Streamlined Planning through Electronic Applications and Referrals (SPEAR) system) has been successful, but only over a period of time. Moving typically paperbased activities to an electronic format (plans, applications, emails) will not only result in administrative savings (KPMG, 2009) but has also been identified as impacting positively on regulatory issues (KPMG, 2010).

The challenge inherent in normative issues is exemplified by the tendency to introduce new technologies without corresponding changes to processes. Relevant to 3D cadastres (and other innovations), it is important to make sustainable use of new digital technologies and leverage the new opportunities they present, rather than use new technologies to simply digitise existing practises as this results only in consolidating existing products and services. For example, The Netherlands was the first country in the world to support a fully electronic conveyancing process with its ELAN system, potentially an important step forward towards 3D cadastres because of the possibility to accept 3D PDFs as part of a deed. However ELAN requires digital legal documents to be a one-to-one representation of the paper version of the document. Therefore a 3D PDF that provides insights into complex 3D property situations cannot be included in the legal documents in ELAN. Instead, other solutions, outside ELAN are needed to accept 3D PDFs as legal documents. The same pitfall can be observed when it comes to other innovations within National Mapping and Cadastral Agencies (NMAs). For example, automated generalisation potentially brings important improvements for map production. However, in practice many NMAs apply this to mimic existing maps, which are managed by standards decades out of date. Also, here the approach to using new technologies to do the same, more efficiently consolidates legacy information structures (i.e. with a focus on using maps rather than on using digital information), which in turn reduces the potential to introduce more modern techniques.

\subsection{Cultural-Cognitive Elements}

According to Scott's framework, cultural-cognitive aspects are the most fundamental component of institutions because they are firmly established at individual or group level and constitute the shared system of values and beliefs that help to construct social reality, and the way in which we create meaning (Scott, 2001). It is so deeply rooted that actors are often not conscious of the influence it has on behaviour. This makes these institutional elements some of the most difficult to discern and therefore, to change.

Our cognitive capacity and sense-making regarding land and property representation has (largely) been oriented towards $2 \mathrm{D}$ representations for a long time, with resultant processes, practices and paradigms. This is evident in maps, drawings and surveying practices. This is not an insignificant consideration: Sandberg (2001: 204) put forward that "if the survey and mapping barriers can be overcome, there should be no legal impediment to implementing three-dimensional division of parcels". Evidence of how persistent these cognitive aspects are can be seen most notably in the use and application of current $2 \mathrm{D}$ registration methods for 3D property, but with some work-arounds, for example, the use of 3D tags in Indonesia. Such use and adaptation of current methods instead of innovating new methods is not uncommon and Section 2 provides a variety of examples. The tendency for people to fall back on either what they know best, what they are used to, or the response which has become most routinised, is is especially prevalent in the face of new and complex situations or technologies (Kaplan and Tripsas, 2008).

In the case of 3D cadastres, planning to introduce and sustainably use new processes and new technologies requires systemic change in the day-to-day processes supporting the land registration and development process. To an extent, the legal mandate of cadastral organisations and their responsibility for legal security of tenure enforces a culture of conservatism towards systemic change. Current systems have proven their legal reliability and essentially, the system is not seen to be 'broken'. There will not be a dedicated drive for change as long as 3D property is, or can be, registered in current systems. This underscores the inertia that cultural-cognitive elements can impose - a preference to 'stretch' current practices to fit 3D property registration although it is less than appropriate simply because these practices are legitimised through repetitive and historical use. This is the case, for example in Denmark and the Netherlands, where the 3D legal object is only registered if both the selling and buying party agree to the registration, specifically when a new 3D property is entered into the system. However, the fact that the register may not give sufficient 
information to future owners at the time of registration is perhaps of lesser importance. The example of the cadastral map in Figure 4 below shows numerous mini-parcels, which is the result of projecting 3D objects above and below the surface on the 2D cadastral map to be able to register the objects via 2D parcels. This particular situation gave no problems when registering the parcels for the concerning objects. However upon transferral of some of the objects, it now appears impossible to identify which parcels belong to which 3D object.

\begin{tabular}{|l|l|l|l|l|l|}
\hline \multicolumn{2}{|l|}{} & & & & \\
\hline & & & & & \\
\hline
\end{tabular}

Figure 4: Many small parcels in a cadastral map resulting from projecting objects above and below the surface in a 2D cadastral map in the Netherlands.

Ultimately, the realisation of 3D cadastres will require broader discourse related to evolving the institution of the terrestrial cadastre to align with modern land administration needs. The current cadastre is under pressure to evolve but to do so, institutions that underpin the entire lifecycle of land and property information management need to be examined. It is fundamentally a paradigm shift in the collection, management and production of land and property information to improve on existing capabilities in representing the legal and physical relationships between land and property interests - and could result in a fundamental change to current principles that govern land and property registration. As Fendel (2002, p.7) summarised in the outcomes of the first 3D cadastre workshop:

\begin{abstract}
"Maybe there needs to be a perception of a cadastral volume instead of a parcel. The 'perception' is a mental map of the world and should be supported by more precise policy, law, administration, technology (visual representation) related to the cadastre. The perception of all aspects of the cadastral object must be $3 D$ before we can deal with an 'explicit' $3 D$ cadastre."
\end{abstract}

These institutional factors, categorised broadly as regulatory, normative and cultural-cognitive, while only briefly touched upon, can go a long way towards enabling researchers' understanding of the social context that $3 \mathrm{D}$ cadastres currently operate within, and the future context it needs to be aligned with. By adopting an appropriate theoretical framework, the research agenda can be enriched with deeper insights into the organisational and institutional aspects affiliated with all aspects of 3D cadastre research, including implementation. This has two significant contributions: at a micro level, an ability to articulate the current 'rules' that prescribe information processes (both technical and sociological) can lead to better understanding of how to fully utilise the capabilities of 3D digital technologies. But importantly at a macro level, such a conceptualisation of institutions can lead to a better understanding of the role of stakeholder organisations in this journey of change in support of modern land administration.

\title{
5. CONCLUSIONS AND FURTHER RESEARCH
}

This paper has reviewed the current body of research around legal aspects of $3 \mathrm{D}$ cadastres to define the legal issues relevant to implementation. For the most part, these have been affiliated with legislation relevant to $3 \mathrm{D}$ property registration. However, when these issues were considered in the context of current practices in jurisdictions with differing levels of legal basis for 3D property registration, it became apparent that many jurisdictions were finding an alternate path forward either within the bounds of its legal framework or in spite of it, given the immediate day-to-day need for 3D property registration for the continued functioning of land markets. This challenges the dominant assumption within the 3D cadastre research domain that attributes the lack of progress towards implementation as resting mainly on legal limitations. However, given that many of the alternative methods that have been developed are based on extant $2 \mathrm{D}$ processes, the paper raised a more pertinent question regarding barriers to implementation: why do these 2D-based processes continue to persist despite growing evidence of their inefficiency and inappropriateness that augments potential risk to longer-term security of 3D property RRRs? What is contributing to process path dependencies that, in turn, hinder the adoption of more appropriate processes and technologies? 
The paper then introduced institutional theory as well as a theoretical institutional framework. These were fundamental in reconceptualising the role that legislation plays, especially if considered as part of a broader landscape of institutional factors. Consequently, in response to the main research question of the paper, "what impact do legal issues have in the implementation of a 3D cadastre?", the paper showed that the legal framework, regardless of its current level of support of 3D property registration, actually plays an enabling role in 3D cadastral implementation, albeit a limited one. This has less to do with the regulatory characteristics typically associated with legislation, and more to do with understanding its broader social function as a means of shared sense-making through the application of an institutional lens (with regards to new registration situations posed by complex 3D situations).

Other institutional factors that were potential sources of inertia were also raised. Although generic in nature, the validity of these suggestions lies in the fact that they are either proven issues endemic to land administration organisations or they are proven influences on successful adoption or diffusion of technological innovation in general. These issues are representative of some of the new insights required in the $3 \mathrm{D}$ cadastre research domain. In conclusion, it is highly likely that the main barrier to cadastral innovation lies not in technological or legal issues, but more fundamental social and cultural issues that make up the institutional framework underpinning cadastral systems and its inherent processes.

This paper is part of an ongoing research project by the authors. Future research will focus on developing a better understanding of the relationship between institutions, organisations and 3D cadastre innovation. An empirical study of the current processes around 3D land and property information transactions in the Australian state of Victoria and the Netherlands is being planned to provide a platform to better understand the organisational and institutional aspects. Specifically, this will focus on using a process-oriented approach to elucidating institutional characteristics and requirements to create a path towards 3D cadastral systems. Unlike legislative issues, there is considerable similarity across jurisdictional boundaries in cadastral processes and research in this area would significantly contribute to international efforts to facilitate implementation initiatives.

\section{ACKNOWLEDGEMENTS}

The authors would like to acknowledge the support of the Australian Research Council, specifically the Linkage Project (LP110200178), and all associated industry partners, and emphasise that the views expressed in this paper are the authors' alone. Special thanks to Assoc. Prof. Kevin McDougall, Ms. Jude Wallace and Mr. Brian Marwick, and last but not least, to the anonymous reviewers, for all constructive and critical review comments.

\section{REFERENCES}

Aien, A., Rajabifard, A., Kalantari, M. and I. Williamson 2011. Aspects of 3D cadastre - A case study in Victoria. Proceedings of the 2011 FIG Working Week: Bridging the Gap Between Cultures. Marrakech, Morocco, May 18-22.

Banut, R. 2011. Overview of Working Sessions. Proceedings of the $2^{\text {nd }}$ International Workshop on 3D Cadastres, 16-18 November 2011, Delft, The Netherlands. Retrieved on 10 January 2013 at http://www.gdmc.nl/3DCadastres/literature/3Dcad 2011 47.pdf.

Burns, T. 2006. International Experience with Land Administration Projects: a Framework for Monitoring of Pilots Land Equity International. Digital report retrieved on 10 January 2013 at http://www.landequity.com.au/assets/Uploads/International-Experience-and-a-Framework-for-Monitoring-ofPilots-Tony-Burns.pdf

Bydlosz, J. 2012. The cadastre in Poland - The current status and possibilities of transformation into 3D one. Proceedings of the FIG Working Week 2012, Rome, Knowing To Manage The Territory, Protect The Environment, Evaluate The Cultural Heritage, Rome, Italy, 6-10 May 2012. Retrieved on 10 January 2013 at http://www.gdmc.nl/3DCadastres/literature/3Dcad 2012 11.pdf.

Damsgaard, J. and Lyytinen, K. 2001. The role of intermediating institutions in the diffusion of electronic data interchange EDI: How industry associations intervened in Denmark, Finland, and Hong Kong. The Inf. Soc, Vol. 17 (2001), 195-210.

Dimopoulou, E. and Elia, E. 2012. Legal Aspects of 3D Property Rights, Restrictions and Responsibilities in Greece and Cyprus. Proceedings of the $3^{\text {rd }}$ International Workshop on 3D Cadastres, Developments and Practices, 25-26 October 2012, Shenzhen, China, pp. 41-60. 
Dosi, G. 1982. Technological paradigms and technological trajectories. Res. Policy, Vol. 11 (1982), 147-162.

Edquist, C. (Ed.) 1997. Systems Of Innovation: Technologies, Institutions, And Organizations. London, UK: Pinter.

Enemark, S. 2004. Building land information policies. Proceedings of Special Forum on Building Land Information Policies in the Americas. Aguascalientes, Mexico, 26-27 October 2004. Retrieved from http://www.fig.net/pub/mexico/papers_eng/ts2_enemark_eng.pdf.

Fagerberg, J. 2004. Innovation: a guide to the literature. In J. Fagerberg, D. Mowery, and R. Nelson eds., The Oxford Handbook of Innovation, Oxford University Press, Oxford.

Fendel, E. M. 2002. Registration of Properties in Strata: report on the Working Sessions. Digital report, accessed on 10 January 2013 at http://www.gdmc.nl/3DCadastres/literature/3Dcad 2001 05.pdf.

FIG, 2012. Introduction. Website of the FIG Joint Commission 3 and 7 Working Group on 3D Cadastres Work plan 2010-2014. Retrieved from http://www.gdmc.nl/3DCadastres/.

Hargadon, A.B. and Douglas, Y. 2001. When Innovations Meet Institutions: Edison and the Design of the Electric Light. Adm. Sci. Q., Vol. 46 (3), 476-501.

Hendriatiningsih, S., Abdulharis, R. and Hernandi, A. 2012. Revisiting the Concept Of Boundary On 3d Cadastre In Indonesia. Proceedings of the FIG Working Week 2012, Rome, Knowing To Manage The Territory, Protect The Environment, Evaluate The Cultural Heritage, Rome, Italy, 6-10 May 2012. Accessed on 16 January 2013 at http://www.gdmc.nl/3DCadastres/literature/3Dcad 2012 19.pdf.

Hollingsworth, J.R. 2000. Doing institutional analysis: implications for the study of innovations. Rev. of International Polit. Econ, Vol. 7 (4/Winter), 595-644.

Huml, M. 2001. How to define real estate: 2D or 3D? Legal view, conditions and experiences in the Czech Republic. Proceedings of the International Workshop on 3D Cadastres (pp. 293-299), The Netherlands: Delft University of Technology.

Iván, G. 2011. 3D cadastre development in Hungary. Proceedings of the Second International Workshop on 3D Cadastres, (pp. 453-460), 16-18 November 2011. Delft: TU Delft.

Kaplan, S. and Tripsas, M. 2008. Thinking about technology: Applying a cognitive lens to technical change. Research Policy, Vol. 37 (2008), 790-805.

Karki, S., Thompson, R., McDougall, K., Cumerford, N. and van Oosterom, P. 2010. ISO land administration domain model and LandXML in the development of digital survey plan lodgement for 3D cadastre in Australia. Proceedings of the 2nd International Workshop on 3D Cadastres (pp. 65-84), 16-18 November 2011. Delft: TU Delft.

Karki,S., Thompson, R.J. and McDougall, K. 2013. Development of validation rules to support digital lodgement of 3D Cadastral plans. Comput., Environ. and Urban Syts., Vol. 39 (2). In press.

Kaufmann J. and Steudler D. 1998. Cadastre 2014: A Vision for a Future Cadastral System. Publication prepared by Working Group 7.1, Commission 7, FIG, July 1998.

King, J. L., Gurbaxani, V., Kraemer, K. L., McFarlan, F. W., Raman, K. S., and Yap, C. S. 1994. Institutional factors in information technology innovation. Inf. Syst. Res., Vol. 5 (2), 139-169.

KPMG, 2009. Measuring Changes in the Administrative Burden Through SPEAR. Report prepared by KPMG for the Department of Sustainability and Environment, August 2009.

KPMG, 2010. Regulatory Change Measurements of Changes in Regulatory Burden from SPEAR. Report prepared by KPMG for the Department of Sustainability and Environment, August 2010.

Leavitt, B., J.G. March. 1988. Organizational Learning. Annu. Rev. of Sociol., Vol.14, 319-340. 
Meyer, J.W. and Scott, W.R. 1983. Organisational Environments: Ritual and Rationality. Beverly Hills, CA: Sage.

Navratil, G. 2012. Combining 3D cadastre and public law - an Austrian perspective. In P. Van Oosterom, R. Guo, L. Li, S. Ying and S. Angsüsser (eds.), Proceedings of the $3^{\text {rd }}$ International Workshop on 3D Cadastres pp. 61-71, 25-26 October, Shenzhen, China 2012. Copenhagen, Denmark: International Federation of Surveyors.

Nelson, R. 1988. Institutions supporting technical change in the United States. In G. Dosi, C. Freeman, R. Nelson, and L. Soete (eds)., Technical Change And Economic Theory pp. 312-329. New York: Pinter.

Nelson, R.R. and Nelson, K. 2002. Technology, institutions and innovation systems. Res. Policy, Vol. 31 (2002), 265-272.

North, D. C. 1990. Institutions, Institutional Change, and Economic Performance. Cambridge: Cambridge University Press.

Orlikowski, W.J. and Robey, D. 1991. Information technology and the structuring of organizations. Inf. Syst. Res, Vol 22, 143-169.

Osskó, A. 2001 Problems in registration in the third vertical dimension in the unified Land Registry in Hungary, and possible solution. Proceedings of the International Workshop on 3D Cadastres, 2001, Delft, pp. 305-314

Ostrom, E. 2005. Understanding Institutional Diversity. New Jersey: Princeton University Press Kindle edition, location 1-7797.

Papaefthymiou, M., Labropoulos, T. and Zentelis, P. 2004. 3D cadastre in Greece - legal, physical and practical issues; application on Santorini Island. Proceedings of FIG Working Week, Athens, Greece, May 22-27, 2004

Paulsson, J. 2007. 3D Property Rights - An Analysis of Key Factors Based on International Experience. PhD Thesis, Real Estate Planning and Land Law, Royal Institute of Technology, Stockholm.

Paulsson, J. 2012. Swedish 3D property in an international comparison. In P. Van Oosterom, R. Guo, L. Li,

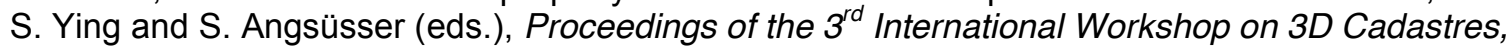
Developments and Practices (pp. 23-40), 25-26 October 2012, Shenzhen, China. Copenhagen, Denmark: International Federation of Surveyors.

Paulsson, J. and Paasch, J. 2011. 3D property research - a survey of the occurrence of legal topics in publications. Proceedings of the 2nd International Workshop on 3D Cadastres (pp. 1-14), 16-18 November 2011. Delft: TU Delft.

Peters, B.G. 2000. Institutional Theory: Problems and Prospects. Political Science Series Paper 69 July 2000, Institute for Advanced Studies, Vienna, Austria. Retrieved from http://www.ihs.ac.at/publications/pol/pw69.pdf on 23 November 2012.

Powell, W.W. 1991. Expanding the scope of institutional analysis. In P.J. DiMaggio and W.W. Powell (eds.), The New Institutionalism in Organizational Analysis pp.183-203. Chicago: University of Chicago Press.

Rajabifard, A., Kalantari, M. and Williamson, I. 2012. Land and Property Information in 3D. Proceedings of the 2012 FIG Working Week, Knowing to Manage the Territory, Protect the Environment, Evaluate the Cultural Heritage. Rome, Italy, 6-10 May 2012. Accessed on 14 Jan 2013 from http://www.gdmc.nl/3DCadastres/literature/3Dcad 2012 16.pdf.

Sandberg, H. 2001. Three-dimensional division and registration of title to land: Legal aspects. Proceedings of the International Workshop on 3D Cadastres, 2001, Delft, pp. 201-209.

Scott, W.R. 2001. Institutions and Organisations. Thousand Oaks, CA: Sage Publications.

Scott, W.R. 2008. Institutions and Organisations: Ideas and Interests. Los Angeles: Sage Publications.

Stoter, J. E. 2004. 3D Cadastre. PhD Thesis. Technical University of Delft. 327pp. 
Stoter, J. and Ploeger, H. 2003. Registration of 3D objects crossing parcel boundaries. Proceedings of 2003 FIG Working Week, Paris, France, April 13-17, 2003.

Stoter, J. and Zevenbergen, J. 2001. Changes in the definition of property: A consideration for a 3D cadastral registration system. Proceedings of the FIG Working Week, Seoul, 2001. Accessed on 10 January 2013 at http://www.gdmc.nl/3DCadastres/literature/3Dcad 2001 01.pdf.

Stoter, J., van Oosterom, P. And Ploeger, H. 2012. The phased 3D cadastre implementation in the Netherlands. In P. Van Oosterom, R. Guo, L. Li, S. Ying and S. Angsüsser (eds.), Proceedings of the $3^{\text {rd }}$ International Workshop on 3D Cadastres pp. 201-218, 25-26 October, Shenzhen, China 2012. Copenhagen, Denmark: International Federation of Surveyors.

Suchman, M.C. and Edelman, L.B. 1996. Legal rational myths: Then new institutionalism and the law and society tradition. Law and Social Inquiry, Vol. 21 (4): 903-941.

Tan, L. C. and Hussin, K. B. 2012. Establishing 3D Property Rights in Malaysia. Proceedings of the 2012 FIG Working Week, Knowing To Manage The Territory, Protect The Environment, Evaluate The Cultural Heritage, Rome, Italy, 6-10 May 2012. Retrieved from http://www.gdmc.nl/3DCadastres/literature/3Dcad 2012 03.pdf on 14 Jan 2013.

Van der Molen, P. 2003. Institutional aspects of 3D cadastres. Comp., Environ. and Urban Syst., Vol. 27 (4), 383-394.

Van Oosterom, P., Stoter, J., Ploeger, H., Thompson, R. and Karki, S. 2011. World-wide inventory of the status of 3D Cadastres in 2010 and expectations for 2014. Proceedings of the 2011 FIG Working Week, Bridging the Gap between Cultures, Marrakech, Morocco, 18-22 May 2011.

Vitikainen, A. and Hiironen, J. 2012. Development Scenarios of the 3D Cadastral System in Finland. Presentation given at the 2012 FIG Working Week, Knowing To Manage The Territory, Protect The Environment, Evaluate The Cultural Heritage, Rome, Italy, 6-10 May 2012. Accessed on 10 January 2013 at http://www.gdmc.nl/3DCadastres/literature/3Dcad 2012 12.pdf

Williamson, I. P. 2002. The cadastral "tool box" - A framework for reform. Proceedings of the $22^{\text {nd }}$ FIG International Congress, Washington DC, U.S.A. , April 19-26.

Yu, C., Li, L., Ying, S., He, B., Zhao, Z. and Wan, Y. 2012. Designing a Title Certificate for the Chinese 3D Cadastre. In P. Van Oosterom, R. Guo, L. Li, S. Ying and S. Angsüsser (eds.), Proceedings of the $3^{\text {rd }}$ International Workshop on 3D Cadastres, 25-26 October 2012, Shenzhen, China, Accessed on 10 January 2013 at http://www.gdmc.nl/3DCadastres/literature/3Dcad 2012 31.pdf.

Zevenbergen, J. and Stubkjær, E. 2005. Real Property Transactions: Challenges of Modeling and Comparing. Proceedings of the 2005 FIG Working Week and GSDI 8, From Pharaohs to Geoinformatics, Cairo, Egypt April 16-21, 2005. Accessed on 10 January 2013 at http://www.fig.net/pub/cairo/papers/ts 11/ts11 04 zevenbergen stubkjaer.pdf.

Zucker, L.G. 1977. The role of institutionalisation in cultural persistence. Am. Sociol. Rev, Vol. 42, 726-743. 